\title{
Sebastian Sathiya Nesan
}

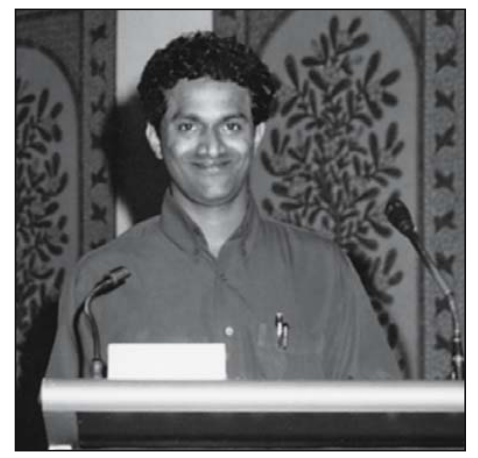

We deeply regret to announce the untimely demise of our friend and colleague Dr. Sebastian Sathiya Nesan on 19 August 2008.

He was born in Tirunelveli, Palayamkottal on $18^{\text {th }}$ May 1968. He graduated from the Tirunelveli medical college in 1991. He completed his MS general surgery in 1998 and MCh cardiothoracic surgery from the Madras medical college in 2002 and subsequently joined the faculty of Madras medical college as assistant professor till 2004. He joined the department of cardiothoracic surgery at the
Sri Ramachandra university in 2005 and was appointed associate professor in 2007.

Sathiya nesan was a happy go lucky guy who lived for the moment and always had a smile on his face. He had a very positive attitude at work and always thought that the impossible was nonexistent. At work he developed a recent interest in pediatric cardiac surgery.

He was a familiar face at our annual and regional conferences. His greatest quality was to make friends easily and without reservation.

We miss his company and will always remember his as a colleague and friend.

He is survived by his wife Mary vanaja, daughter Mariana chatrian and son Kevin mcenroe. We extend our heartfelt condolences to the bereaved family. May his soul rest in peace.

Dr. Richard Saldanha 